\title{
Analysis of Employees' Professional Development in a Forensic Science Laboratory as a Route towards Organizational Competitiveness
}

\author{
Samwel Victor Manyele ${ }^{1}$ Nancy Osmund Nomboํ, Gloria Cuthbert Omari², George Mwaluko² \\ ${ }^{1}$ Government Chemist Laboratory Authority, Dar es Salaam, Tanzania \\ ${ }^{2}$ Department of Mechanical and Industrial Engineering, University of Dar es Salaam, Dar es Salaam, Tanzania \\ Email: gcla@gcla.go.tz,sammanyele@gmail.com, mwalukogeorge@yahoo.com
}

How to cite this paper: Manyele, S.V., Nombo, N.O., Omari, G.C. and Mwaluko, G. (2017) Analysis of Employees' Professional Development in a Forensic Science Laboratory as a Route towards Organizational Competitiveness. Engineering, 9, 1018-1047. https://doi.org/10.4236/eng.2017.912061

Received: November 11, 2017 Accepted: December 26, 2017 Published: December 29, 2017

Copyright $\odot 2017$ by authors and Scientific Research Publishing Inc. This work is licensed under the Creative Commons Attribution International License (CC BY 4.0).

http://creativecommons.org/licenses/by/4.0/

c) (i) Open Access

\begin{abstract}
This study was conducted to analyze the competitiveness of a Forensic Science Laboratory (FSL) based on employees' professional development and diversification into different professions. The FSL is the sole Government Laboratory in Tanzania which serves the police force, judiciary system and the public prosecution. A sample of 88 current employees of different professions (53 chemists, 26 technologists and 9 accountants) was used. The data was collected from the year 2000 to 2015. Mathematical expressions were developed to quantify stagnation and total service time at specific development levels based on which new indices (professional development index, $P D I$; leadership competency index, $L C I$; and succession index, $S I$ ) were developed. The number of employees for support cadres was observed to increase faster in the last 5 years from $34.3 \%$ in $2009 / 2010$ to $57.1 \%$ in $2014 / 2015$, compared to chemists and technologists. The staff-to-line ratio (SLR) has been increasing since 2000, reaching above 0.8 from 2013 to 2015 indicating that the FSL was undergoing diversification and division of labor. The FSL workforce comprised of mainly semi-skilled employees. Promotions have played a big role in employees' professional development. In some cases employees were promoted to higher level before 3 years stipulated by public service regulations, regarded as breach of procedures. However, high stagnation of employees at specific ranks was observed (up to 9 - 10 years) which causes frustrations, lost morale and engagement. Results indicated that most of the service years are served in ranks A and B. Indices developed in this study form a baseline data for strategic analysis of FSL competitiveness in the future and allow for proper human resource planning. Highest values of $L C I$ and $P D I$ were observed for chemists. Technologists in the FSL show higher succession index compared to chemists and accountants. Employee diversification in the
\end{abstract}


FSL has been increasing from 2003 to 2015. It was concluded that the FSL competitive advantage is continuously increasing.

\section{Keywords}

Professional Development, Forensic Science Laboratory, Employee Stagnation, Total Service Years, Leadership Competency Index, Professional Development Index, Succession Index, Staff-to-Line Ratio, Diversification Index

\section{Introduction}

The government Chemist Laboratory Authority (GCLA), the sole FSL in Tanzania, is currently in a transition to change from an agency to an authority with increased powers and responsibilities. As a result, there is high demand on human resource to undertake the changes and maintain its competitive edge. This has forced the GCLA to scientifically assess the existing workforce structure and employee professional development plans [1] [2]. There are numerous factors causing the FSL to revisit its workforce structure, but three key elements are influencing this national FSL, in particular. GCLA has both forensic and non-forensic laboratories to provide services to the government and the public in a competitive market. A struggle for modest growth of the organization is a good effort but more employees will be needed to accommodate growth, lack of which hampers strongly smooth growth of this organization. A second element is regulation changes whereby, health insurance costs and social security funding laws influence the organization growth in terms of acquisition of new employees in the public sector. Legal provisions have spurred employers to begin contemplating the size and structure of the workforce in Tanzania (Ref). Lastly organizational growth comes with hard cost increases, for instance, increase in minimum wages and extra duty payments adds to employer labor costs in both public and private sector. These hard cost increases put more pressure on the FSL's bottom line which necessitated the assessment to determine if the FSL is staffed appropriately. This paper gives scientific methods developed for assessing the workforce expansion using forensic science laboratory as a case study.

The above outside factors affecting the FSL growth are creating the pressure that's driving the FSL to look at the workforce structure and check if changes are needed to support growth in the preceding years. This study addresses employee stagnation, employee diversification, service years and introduces new indices for assessing the workforce size and structure in the FSL.

Allowing employees to stagnate may lead to turnover which affects organizations negatively. When employees are stagnating at their current workplace and feel that the ability to add value to their existing profile has ceased, they start exploring other opportunities. The problem addressed in this study is stagnation due to lack of promotion and slow professional growth among FSL employee. Employee retention levels are determined by organizational policies like training 
programs. The FSL has put efforts in grooming internal talent by offering various training programs, to enable promotion and professional development of its employees.

The workforce studied in this paper comprise mostly full-time permanent and pensionable employees with high potential for productivity and service consistency due to high retention, strong employee loyalty, more solid team unity and a great ability to promote from within. Full-time workforces, however, tend to carry higher compensation and benefit costs which was not considered in this study. Thus, it is critical that employers are committed to building the workforce strategically, even if it may take a little longer to find the best employees. This paper offers tools for assessing the workforce structure.

Having the right employees in the right positions is critical because a strong team can yield benefits such as reduced turnover, increased sales, improved customer service, etc., achieved by good placement, which has gained merits from recruiting directly from the existing workforce. Thus, employee's professional and leadership development is essential, which form the focus of this study. As a result of extended stagnation, low morale can lead to a disconnect between employees and their jobs that may cause them to take short cuts and not pay attention to details, or simply not care whether or not they do the right thing, which can be disastrous for workplaces like FSL.

Professional development refers to activities and interaction among employees that can increase ones knowledge and skills to improve work practice and contribute to their personal and emotional growth. The FSL is a knowledge-intensive organization (KIO), which requires continuous professional growth of employees via studies and long term experience [3]. The term professional development can be used interchangeably with the term employee development [1]. Moreover, the FSL is a professional service organization (PSO) serving the industry, the judiciary, the police investigation and prosecution [4]. Professional development is important to FSL because of the many reasons: ensures that employee capabilities are enhanced with current standards, allows maintaining and enhancing required skills for delivery of a professional service to clients, customers and the community and gain organizational competitiveness. Professional development ensures employee knowledge stay relevant and up to date.

Professional development, on the other hand, is being strengthened in the FSL to help individual staff to continue making meaningful contributions to the team and become more effective in the laboratory. Solid career development paths exist to assists employees to advance forward and move into new positions where they can lead, manage, influence coach and mentor others and make good number of successors for business continuity. This is because professional development increases employee commitment after being exposed to new knowledge and skills, helps employee advancement in terms of knowledge and technology within their profession [1] [3] [4]. Moreover, professional development contributes to improved protection and quality of life.

Career plateaus are acute points in a person's career path where progression 
seems difficult or obstacle-ridden, due to both internal and external reasons such as government mechanism on check and balance of the wage bill related to the ability of the government to pay as well as personal efforts of individual employee towards career advancements [5]. To resolve this issue, FSL intends to upgrade its sources of revenue and prepare a proposal to request consent to determine the development issues of its employee that have financial implications. This paper assessed how well professional development is being achieved in the FSL. Stagnation, on the other hand, is defined as to become static, stop developing, growing, progressing or advancing, which is unhealthy both for the employee and employer. Employee stagnation can lead to complacency, reduced productivity and demotivated talents due to blocked promotion prospects, detrimentally affecting the FSL.

Stagnation in the workplace reduces organization's ability to compete. When people get too set in their ways and move into a management position they are likely to hold back younger or more progressive employees. They fear change because they feel they may not be as good at something new as they are at their current ways. Stagnant employees who have set and reached their own limits prevent the organization from expanding its limits and competing with other more progressive companies. They often cause the more innovative employees to leave their current organization and join competitors. Whenever such a shift happens a big gap is created in the laboratory processes.

Stagnant employees in a management position, for instance, often produce a negative, uncooperative, self-defensive and self-destructive culture. They are generally unhappy people who infect others with their bad attitudes. Younger progressive employees, who do stay at the company, sometimes turn into the next generation of the stagnated employee and tend to keep the cycle going. This paper assessed the stagnation times and converts total service time in years into new measures of professional development and leadership capability indices.

There exists a relationship between employee competence and organization competitiveness. Competitiveness means organization's ability to maintain and gain market share in its industry. The value of a laboratory service, for instance, is determined by the quality and how closely the service fits customer needs and the reputation of the organization [6]. Competitive business environment demands frequent changes in quality, innovation, and creativity in service delivery. A competent employee bears such characteristics; therefore human resource practices have a positive influence on the organization's bottom line [7].

The FSL in Tanzania has also gained a competitive advantage due to the fact that its services are unique, valuable and non-imitable by other laboratories. The selected forensic laboratories (toxicology, chemistry and biology/DNA) are highly complex laboratory settings requiring special skills, which cannot be acquired in short time. Such laboratories require long experience to build and are also resource intensive, including highly developed human resource in terms of innovativeness and rich FSL culture [8]. The FSL has emerged from a long way since 
1895, competing against a large number of both private and public laboratories inside and outside Tanzania, gaining a competitive advantage, as a national referral laboratory. The strategy has been to focus the human resource capabilities and competencies towards its core business of forensic science services and satisfy its customers in the country [6] [7]. This study addresses also diversification strategy in employee categories (by comparing the number of support staff to laboratory employees), organization size growth (in terms of number and mix of employees), stagnation, recent spatial growth (expansion into zonal laboratories) and placement of employees in different zones in order to capitalize the market.

Figure 1 shows the conceptual framework for critical components of an organization that lead to competitive advantage. According to this model, employee development is assumed to emanate from employee's own attitude and opportunities available. When employees are developed they become competent [2]; however, competent employees require good leadership to produce desired performance that meets customer satisfaction [6]. Figure 1 shows that a mix of competent employees and good leadership leads to organization's competitive advantage [9]. Therefore, customer satisfaction (which is a measure of competence within an organization) is also the product of right treatment of employees by their leaders. Table 1 shows the sources of competitive advantage for the FSL.

This study aims at assessing the FSL's human capital expansion, history of employment and promotions, staff-to-line ratio (SLR) for the existing line and staff organization (LSO) structure, employee stagnation time for different professions in the FSL and professional development. The study went further quantifying the total service time for all employees in different professional levels based on which, different new indices were developed such as professional development index (PDI), leadership competence index (LCI), diversification index (DVI) and succession index (SI).

\section{Literature Review}

\subsection{Human Resource Planning for Gaining Competitiveness}

Human resource planning may be defined as the process by which management

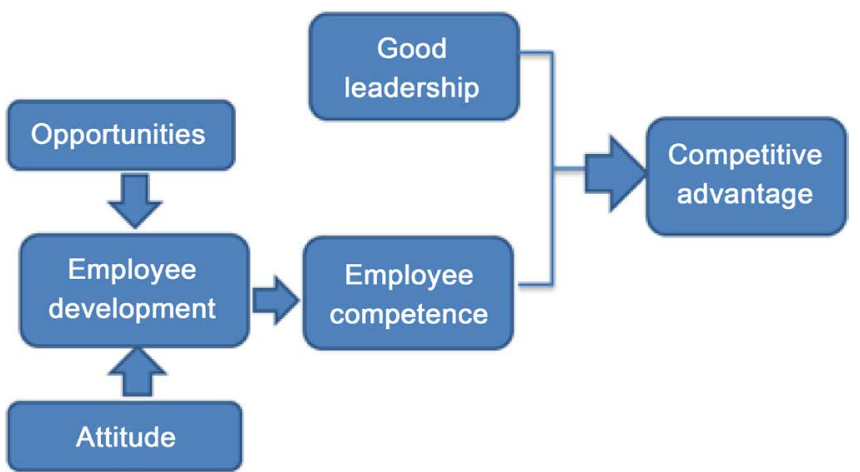

Figure 1. Components of organization competitive advantage. 
Table 1. Sources of competitive advantages for the FSL.

\begin{tabular}{|c|c|}
\hline Source & Description \\
\hline $\begin{array}{l}\text { Employee specific } \\
\text { skills }\end{array}$ & $\begin{array}{l}\text { These refer to skills that are possessed by individuals that provide value to the } \\
\text { FSL and are not transferable across a variety of firms. Specific skills are of no } \\
\text { value to competing firms, for example, the knowledge of how to use a particular } \\
\text { technology used only by one firm is not valuable to other firms. }\end{array}$ \\
\hline $\begin{array}{l}\text { Organization } \\
\text { capability }\end{array}$ & $\begin{array}{l}\text { Organization capability to invest in human resources and build positive attitude } \\
\text { of an employee towards professional development helps an organization to increase } \\
\text { employee competence and gain competitive advantage. }\end{array}$ \\
\hline $\begin{array}{l}\text { Employees } \\
\text { competence }\end{array}$ & $\begin{array}{l}\text { Competence is the ability of an individual to do a job properly. It may also be a } \\
\text { combination of practical and theoretical knowledge, cognitive skills, behavior, } \\
\text { and state of being adequately or well qualified. Employee competence is a product } \\
\text { of professional development, which creates a pool of successors as well as } \\
\text { making effective teams throughout the organization, an aspect which is quite } \\
\text { necessary for gaining competitive advantage. }\end{array}$ \\
\hline $\begin{array}{l}\text { Employee } \\
\text { engagement }\end{array}$ & $\begin{array}{l}\text { Employee engagement is the degree to which employees are fully involved in } \\
\text { their work and the strength of their commitment to their job and the organization. } \\
\text { Work engagement and commitment in professional service firms like FSL is an } \\
\text { important aspect of competitiveness as it leads to higher productivity, better } \\
\text { customer service and lower turnover. }\end{array}$ \\
\hline Team production & $\begin{array}{l}\text { The team production refers to production process in which numerous categories } \\
\text { of human resources are used. In a team production individuals become linked } \\
\text { in operation and specific relationships, resulting in transaction of specific human } \\
\text { capital, involvement in socially complex relationships that are not transferable } \\
\text { across organizations. }\end{array}$ \\
\hline $\begin{array}{l}\text { Human resource } \\
\text { systems and } \\
\text { practices }\end{array}$ & $\begin{array}{l}\text { The interrelatedness of the human resource system makes it difficult for } \\
\text { competitors to identify and copy. This requires investing time and energy into } \\
\text { developing systems and structures for integrating various HR practices. }\end{array}$ \\
\hline
\end{tabular}

determines how the organization should move from its current manpower position to its desired position [2], in terms of the right number and the right kinds of people taking into consideration of the level of education and field of study related to forensic science services. The role of human resources management is to keep the human capital competitive on the market and the logical grouping of human resource processes. This helps to connect and manage the individual processes. The quality assurance guidelines for FSLs performing different disciplines provide a baseline from which laboratories may structure their human resource, which specifies what is to be done and how. Standard operating procedures (SOPs) are required for all forensic science laboratory activities, based on which specific responsibilities of the human resource are established.

The role of HR in gaining competitive advantage focuses on the characteristics of a firm's human resources including knowledge, experience, skills, attitude, commitment and their relationships with each other and those outside the FSL. While these characteristics can provide a firm with a source of competitive advantage often it is difficult to specify which characteristics do so. Moreover, only few of such 
characteristics can be easily measured, such as knowledge, experience and skills while other characteristics are difficult to quantify.

\subsection{Evaluating Supply and Demand of Human Resource}

This study focused on internal staffing analysis, the employment rate into FSL based on government laws and regulations that can affect the FSLs services [9]. A significant part of planning for human resources is forecasting demand. Initially, one has to think of where the business is headed with its trades and income. Furthermore, inadequate number of employees to perform such tasks means the services rendered by the FSL won't be delivered according to the demand which may turn away otherwise happy customers [2], or the organization piles up unattended obligations like chemicals inspection and registration, laboratory inspection and backlogs of case-files waiting analysis and reporting. Forecasting has long been significant to marketing practitioners. Similarly, for FSL to be managed well, one has to forecast the human resource [10]. For instance, the technology change may cause backlog if the management of the FSL does not keep track on the employee performance due to lack of experience or skills.

\subsection{Sources of Career Plateau or Stagnation for FSL Employees}

When employees perceive that they have reached a plateau, their careers are sometimes so affected that their conviction becomes self-fulfilling. At the same time, employees who appear to be plateauing are not necessarily unhappy or inferior. Leveling-off periods are healthy and productive in an adult's development. That is, the so-called plateau could represent a period of stability, where employees master work skills, pursue special family or personal interests; and improve functional, professional, and personal skills so that they can contribute more to their organizations. Thus, turning stagnation time into service time was an import aspect of this study. The objective side of career plateaus relates to the fact that they can be observed measured and analyzed. Measurements, like future prospects for promotion, length of time in present position, or length of time between promotions have been measured in this study. Career plateaus can be damaging to the employee as well as to the organization. Researchers have identified six sources of career plateaus: individual skills and abilities, individual needs and values, lack of intrinsic motivation, lack of extrinsic rewards, stress and burnout, and slow organizational growth [11]. Obviously, all six factors are not inherently negative. Table 2 shows the reasons for reaching career plateau among FSL employees.

\subsection{Knowledge Asset and Transferability among the FSL Employees}

Knowledge assets are at the heart of the competitive advantage of knowledgeintensive firms, such as professional service firms (PSFs) like forensic science laboratory [13] [14]. These knowledge assets can take the form of "know-what" 
Table 2. Major reasons for reaching career plateau among employees.

\begin{tabular}{|c|c|}
\hline Reason for stagnation & Description/remarks \\
\hline Work attitude & $\begin{array}{l}\text { When employees have negative attitude towards work they may opt not } \\
\text { to put efforts towards professional development. }\end{array}$ \\
\hline Worker age & $\begin{array}{l}\text { Older workers appear less likely to participate in continual developmen } \\
\text { because of differences in physical/biological, psychological/mental, and } \\
\text { social dimensions with younger counterparts due to changes caused by } \\
\text { aging. }\end{array}$ \\
\hline Reaching the last rank & $\begin{array}{l}\text { Reaching a specific level of seniority at the Organization where there is } \\
\text { limited chance for higher position. }\end{array}$ \\
\hline Lack of confidence & Development training can help individuals increase confidence. \\
\hline $\begin{array}{l}\text { Labor laws, rules, } \\
\text { regulations }\end{array}$ & $\begin{array}{l}\text { Employee development procedures within public service, according to the } \\
\text { Tanzania Public Service Act. No } 8 \text { of } 2002 \text {, which requires employee to } \\
\text { fulfill specified requirement before promotion. }\end{array}$ \\
\hline Lack of self-efficacy & $\begin{array}{l}\text { Missing capacity to execute behaviors necessary to produce specific } \\
\text { performance attainments and hesitation to engage themselves into } \\
\text { development activities [12]. }\end{array}$ \\
\hline $\begin{array}{l}\text { Lack of funding for } \\
\text { training }\end{array}$ & $\begin{array}{l}\text { Constrained funding for training is the biggest obstacle in accessing } \\
\text { career or professional development. }\end{array}$ \\
\hline $\begin{array}{l}\text { Lack of time to attend } \\
\text { training }\end{array}$ & $\begin{array}{l}\text { Lack of time to attend training courses is an important obstacle, even } \\
\text { where funding was available (e.g., due to family and social issues). }\end{array}$ \\
\hline Wrong perception & $\begin{array}{l}\text { The feeling among employees that the pressures of money and time } \\
\text { meant that any new skills that they had to pick had been developed by } \\
\text { default. }\end{array}$ \\
\hline
\end{tabular}

or "know-how". Individual knowledge on its own is insufficient to create competitive advantage. It is only when knowledge is shared at the collective level that the organization can leverage the knowledge held by individuals. In an organization, knowledge is shared via succession from highly skilled to unskilled or semi-skilled employees, as discussed later using succession index.

The process of knowledge sharing is, however, controlled by the employee [4]. Previous research indicates that employee attitudes, such as their level of commitment, are central to this individual control and their subsequent knowledge sharing with semi-skilled employees [15] [16] [17]. Professionals are, however, committed not only to the organization that employs them but also to the teams in which they work and the clients for whom they serve [18]. Experienced analysts are, for example, more likely to share their knowledge within their team if they are committed to that team.

The impact of employee commitment on knowledge succession is especially important in the FSL. Work within FSL takes place both within and across organizational boundaries, e.g., sampling and inspection. Professional employees interact with a series of professionals, such as police investigators, clients, who are outside the firm, like chemical dealers and, prosecutors during court sessions planners, accountants, and bankers during budget presentation and financial trans- 
actions, etc. Some of these parties provide additional, and often competing, foci of commitment [19]. The professional staff in the FSL faces a series of tensions when their personal control over their knowledge is combined with cross-boundary working. Their knowledge sharing with colleagues may be limited when they feel torn between their commitment to different internal and external parties with whom they interact [3].

\subsection{Importance and Challenges of Workplace Diversification}

Workplace diversity refers to the variety of differences between people in an organization such as line and staff category and different professions. In this study, diversity implies professional integration or mixing between chemists, technologists and accountant, although other professions exist, such as procurement and supplies officers, legal officers, auditors and registry and documentation officers. Diversity not only involves how people perceive themselves, but how they perceive others, because perceptions affect the interactions [8]. For a wide assortment of employees to function effectively as an organization, human resource professionals need to deal effectively with issues such as communication, adaptability and change. Successful organizations recognize the need for immediate action and are ready and willing to spend resources on managing diversity in the workplace now.

An organization's success and competitiveness depends upon its ability to embrace diversity and take advantage of the benefits. Organizations employing a diverse workforce can supply a greater variety of solutions to problems in service, sourcing, and allocation of resources. Employees from diverse backgrounds bring individual talents and experiences in suggesting ideas that are flexible in adapting to fluctuating markets and customer demands. Organizations that encourage diversity in the workplace inspire all of their employees to perform to their highest ability. Organization-wide strategies can then be executed, resulting in higher productivity, profitability and return on investment.

Workplace diversity fosters mutual respect among employees. Whether employees work in groups or teams comprised of co-workers with varied work styles, or colleagues who represent different cultures or generations, a synergistic work environment become the norm. Respect for co-workers either reduces the likelihood of conflict or facilitates an easier road to conflict resolution. The ability to resolve workplace conflict minimizes potential liability for employee complaints and litigations. Workplace diversity preserves the quality of employees' relationships with their co-workers and their supervisors [8]. Moreover, in organizations with poor diversity, employees have to stay too long in the same job and same level [5] [20]. Workplace diversity creates opportunities for companies to get broader perspectives on business situations and to improve global reach, but it does often create some negative impacts in the company.

Diversity in the workplace manifests itself in building a great reputation for the organization, leading to increased profitability and opportunities for work- 
ers. Workplace diversity is important within the organization as well as outside. When human resources channels and harnesses varied skills, specialized competencies and distinctive capabilities of employees, it can result in creative solutions for problems and better organizational productivity. There is significantly more internal movement in diversified laboratories than in focused counterparts. We also find that workers fare significantly better when they change jobs internally than when they change firms, particularly when they also switch industries. Workforce diversity can bring about an increase in productivity and competitive advantages. Employers can offer more solutions to customers because of new ideas and processes brought into the organization.

Taking full advantage of the benefits of diversity in the workplace is not without its challenges. Resistance to change arises when some employees refuse to accept the fact that the social and cultural makeup of their workplace is changing. Organizations that employ diverse workforces encourage different perspectives and promote learning from alternative perspectives. Leaders must be ready to accommodate diverse workforce dynamics. The key to employing a diverse workforce is to train and support managers within the organization. Managers must understand the need to support individuals within the team, balancing conflicting needs and opinions.

In a diversified workplace each team member must have the opportunity to be heard and feel that their opinions are respected. Managers also need to understand and deal constructively with their own biases and prejudices. By offering opportunities to all employees based on their performance, a company can increase its productivity and creativity [21]. Human resource practices fostering more flexible work design are critical in ensuring a balance between employee's commitment to their organization, and their profession [22].

\section{Methodology}

\subsection{Sample Size for the Study}

The sample size comprised of 88 (about $46 \%$ of all GCLA employees) comprising of different categories or professions (53 chemists, 26 technologists and 9 accountants, representing support staff) was used in this study as summarized in Table 3. The employee data was downloaded from the human resource database which covers the period from the year 2000 to 2015 .

Table 3. Designation of the different ranks for different FSL professions (chemists, technologists and accountants).

\begin{tabular}{cccc}
\hline Rank & Chemists & Technologists & Accountants \\
\hline E & Principal Chemist I - To Date & Principal Technologist I - To Date & Principal Accountant I - To Date \\
D & Principal Chemist II - Principal Chemist I & Principal Technologist II - & Principal Accountant II - \\
& Principal Accountant I \\
C & Senior Chemist - Principal Chemist II & Senior Technologist - Principal Technologist II & Senior Accountant - Principal Accountant II \\
B & Chemist I - Senior Chemist & Technologist I - Senior Technologist & Accountant I - Senior Accountant \\
A & Chemist II - Chemist I & Technologist II - Technologist I & Assistant Accountant - Accountant I \\
\hline
\end{tabular}


The data used was uploaded from the human resource department. It involved categorization of employees according to cadre and their profession. There exists specific stages of professional development among employees whereby, the starting level for the accountant profession starts with assistant accountant, whereas, the technical professions start with grade II (for the chemist or technologist). This means that there are six stages of development for accountants, whereas the technical professions have five stages. It was then agreed that, the starting rank for accountants to combine the two steps (assistant accountant to accountant II, and accountant II to I) so as to have equal number of levels for simplicity of analyzing the data, as shown in Table 3.

To establish the stagnation time during their professional development, data was collected from the employee's professional development database within the FSL. For all employees, the stagnation values in each cadre were determined in the sampled groups from which the average, maximum and minimum observed values were established for the five cadres in each profession, shown in Table 3. Stagnation time, $y_{i}$ was defined as the time in years from initial date of promotion into a given rank (denoted as, $t_{i}$ ) to the final date employee is promoted to the next cadre $\left(t_{f}\right)$, as per Equation (1):

$$
y_{i}=\left(t_{f}-t_{i}\right)
$$

\subsection{Distribution of Employees among Different Professional Levels}

Figure 2 shows the percent of employees in each professional level for accountants, technologists and chemists based on the employee sample used in this study. None of the accountants were observed in the principal level, while a good number of technologists were in principal level. Level D (senior level) shows

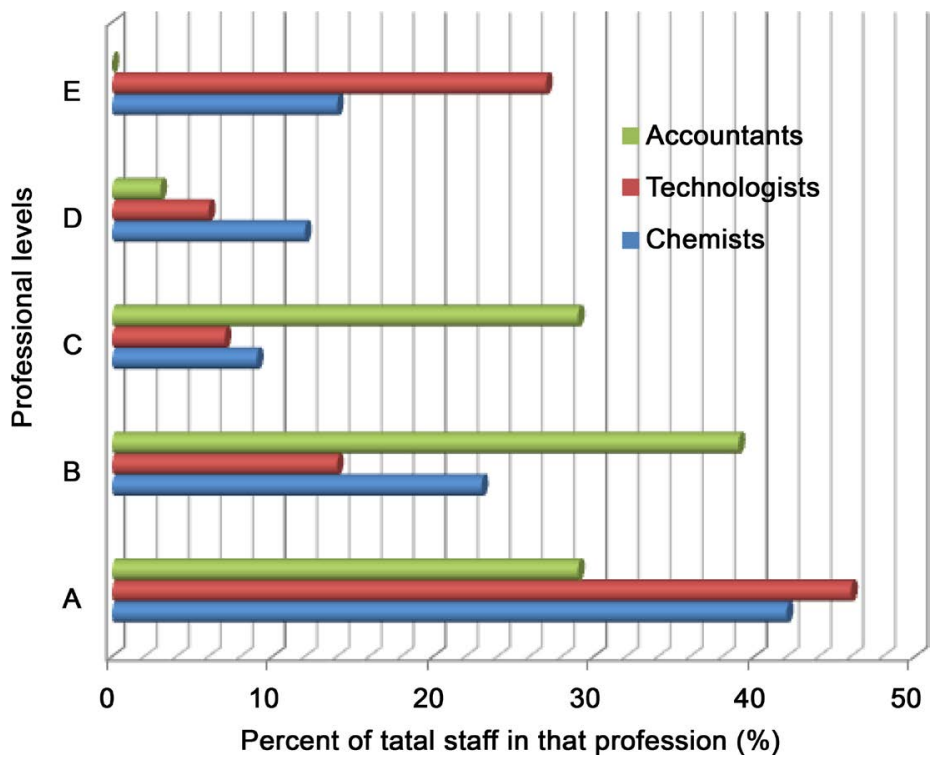

Figure 2. Percentage of employees in specific professional development levels based on the sample size. 
lower number of employees for all professions compared to levels A and B with high percentage of employees.

\subsection{Determination of Stagnation or Service Time}

Let $k=$ number of professional development levels (i.e., $k=1,2,3,4,5$, for the cadres A to E); and, let $i=$ number of employees in the selected three professions, that is, $i=1,2,3, \ldots, N$ (where $N$ is the total number of employees in the professional sample, $N=53$ for chemists, 26 for technologists, and 9 for accountants). Thus, the total number of years for which the FSL employees served at those cadres, A to E, also defined as competence volume, denoted as $\Omega$, can be calculated from Equation (2):

$$
\Omega_{k}=\sum_{i=1}^{N} y_{i}
$$

The overall or grand total stagnation, a measure of total longevity for the sample of employees, denoted as $\Omega_{\text {tot }}$ for all professional development levels combined, A to E, was determined based on Equation (2). The stagnation in the principal level E, cadres denoted as $\Omega_{E}$ signifies the measure of FSL competency capability, that is, the time in years employees served in as principal officers, and is supposed to be higher when more FSL employees serve more years in the most senior professional levels. On the other hand, $\Omega_{E D C}$ is a measure of FSL's leadership capability since employees in these three levels can be assigned leadership roles, depending on their performance. The lower ranks in levels A and B serves the FSL as they develop, total time of which was denoted as $\Omega_{A B}$.

\subsection{Establishment of Professional Development Index}

Based on Equation (2), the professional development index, $P D I$, for lower cadres, is defined as per Equation (3):

$$
P D I=\frac{\Omega_{A}+\Omega_{B}}{\Omega_{\text {tot }}}
$$

\subsection{Establishment of Leadership Competence Index}

The general FSL leadership competency index, $L C I_{g}$, for the senior cadres, is defined using Equation (4):

$$
L C I_{g}=\frac{\Omega_{C}+\Omega_{D}+\Omega_{E}}{\Omega_{\text {tot }}}
$$

It should be noted that, when only $\Omega_{E}$ is used to compute the leadership competency index, then specific index, $L C I_{s}$, is referred to, otherwise a general index is implied. That is, specific leadership competence index is defined as per Equation (5).

$$
L C I_{s}=\frac{\Omega_{E}}{\Omega_{\text {tot }}}
$$

For the FSL to be competitive in its business focus $L C I$ must be less than PDI. 
Moreover, the leadership competency and professional development indices should increase with time, as the senior cadres become more innovative and requiring the lower cadres to implement the new routines.

\subsection{Succession Index}

For a good succession program, when $L C I$ increases, the FSL should increase the volume of $P D I$ in order to generate income based on return from innovations created by professional employees, and also to prepare the new employees to take over as the seniors or professionals retire. A measure of succession capability in the organization, defined as succession index $S I$, is the ratio between $L C I$ and PDI for each profession, as per Equation (6):

$$
S I=\frac{L C I}{P D I}=\frac{\Omega_{E}}{\Omega_{A B}}
$$

\subsection{Derivation for Diversification Index}

For each financial year, diversification index, $D V I$, was defined as the ratio of the number of additional support staff to the total number of laboratory cadres (chemists and technologists). Let $N_{L S}$ be the total number of laboratory or line staff during a given financial year and $N_{s a}$ be the number of support staff added as new employees of FSL in the same year, then diversification index, DVI is defined as per Equation (7):

$$
D V I=\frac{N_{s a}}{N_{L S}}
$$

\subsection{Derivation of Staff-to-Line Ratio}

The ratio of total number of support staff, $N_{s s}$ to the total number of laboratory staff, $N_{L S}$, is defined as the staff-to-line ratio, $S L R$, given as per Equation (8):

$$
S L R=\frac{N_{S S}}{N_{L S}}
$$

\section{Results and Discussion}

\subsection{Employment History in the FSL from the Year 2000 to 2015}

Employment has been a key issue in the Government institutions for many years. Shortage has been a substantial problem in terms of numbers, professional types, skills and experience. In order to assist the human resource (HR) planning, it was necessary to assess the situation critically for several years before this study, as shown in Figure 3.

Figure 3 shows that before 2003, there were few chemists compared to technologists, a situation which changed afterwards. To date, the number of chemists has been increasing faster reaching above 40 compared to technologists which remained below 30. From 2012 to 2015, the number of support cadre has increased from 45 to above 100. This is due to that fact as the FSL expands its services 


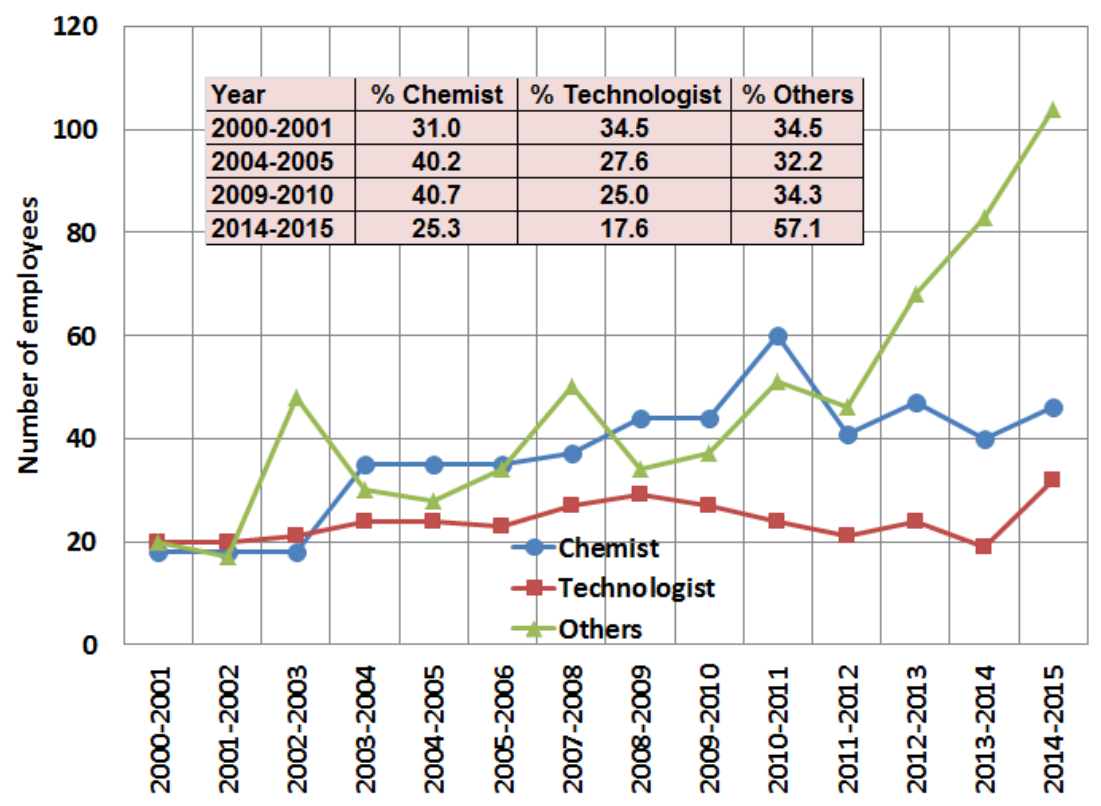

Figure 3. Employment time series by categories of employees within the FSL.

to reach the rest of the country, there is a high demand for support cadres to take care of finances, documentation and registry, human resources management, systems audit, procurement management, ICT facilities and networks, secretarial work, drivers, etc.

\subsection{Status of Staff-to-Line Ratio in the FSL}

There are two types of employees in the FSL (that is, laboratory personnel and support cadres). Thus, the FSL is regarded as line and staff organization (LSO). This type of organization is a compromise of line organization with a strong division of work and specialization. The whole organization is divided into different functional areas (as per organogram) to which employee are attached. It is evident that efficiency and competitiveness can be achieved through the features of specialization. Based on the nature of business focus which involves forensic science services, regulatory functions for chemicals, DNA services and laboratories, there are two lines of authority which flow at the same time, that is, line authority and staff authority. Moreover, the power of command remains with the line executive and staff serves only as counselors. Figure 4 shows the variation staff to line ratio (SLR) with time from the year 2000 to 2015. According to Figure 4, the SLR has been rising from 0.1 in 2001 to above 0.8 from 2013 to 2015. The last three financial years, have witnessed high rise in SLR, completely diluting the line authority in terms of numbers. The reasons for increasing the number of staff members follows the emphasis from the government to use appropriate professions in implementing various roles as well as implementing organizational structures that focus on it. This increase in SLR has advantages and disadvantages (if not well managed).

The increase in SLR partly demonstrates workplace diversification, discussed 


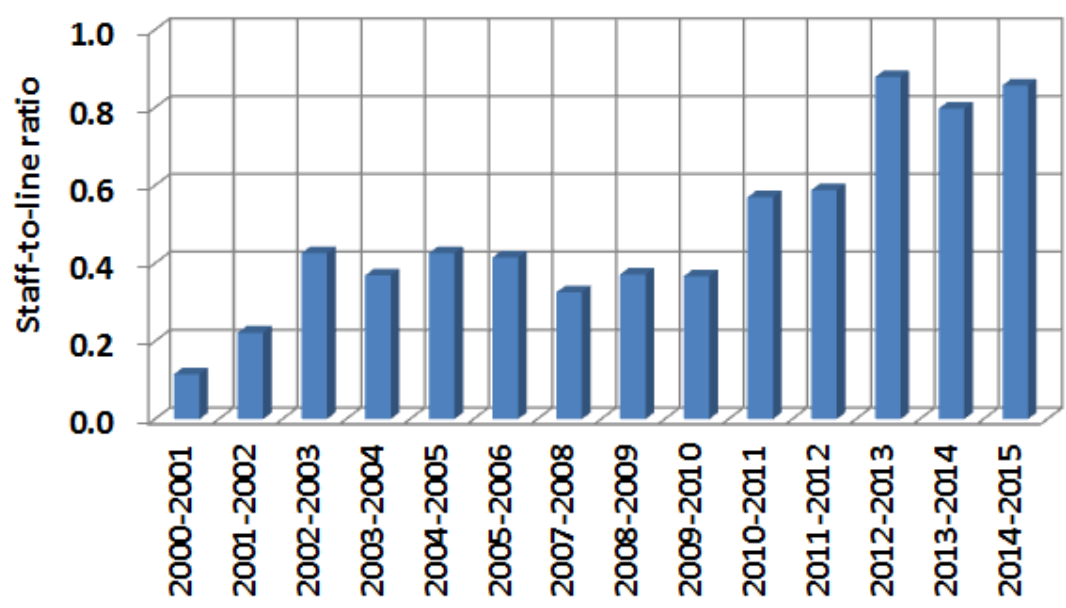

Figure 4. Variation of staff-to-line ratio (SLR) with time from the year 2000 to 2015.

later in this paper. There are several merits of line and staff organization system adopted by the FSL. One of the advantages is relief for line executives. In the FSL under study, the advice and counseling which is provided to the line executives divides the work between the two. The line executive can concentrate on the execution of plans and they get relieved of dividing their attention to many other areas like finance, procurement, registry and documentation to mention a few. Given the importance of maintaining quality and accuracy of analytical results, maintaining databases of chemicals and dealers and laboratory information system, the importance of having support cadres remains paramount.

Another merit of high SLR is the availability of expert advice from support cadres. The line and staff organization facilitates expert advice to the line executive at the time of need. This role needs to be emphasized for successful performance of the FSL. The FSL through specialization is able to provide better decision making and concentration remains in few hands. This feature helps in bringing co-ordination in work as every official is concentrating in their own areas. Moreover, line executives can give due concentration to their decision making for progress and competitiveness of the FSL. Unity of action is another merit of organizational type existing in the FSL, whereby, all the officials have got independence to make decisions. This serves as an effective control in the whole enterprise.

However, there exist some demerits of LSO adopted by the FSL. Lack of understanding, especially when the workers are not able to understand who is their commanding authority, may lead to hurdles towards effective running. Also, when specialists provide wrong decisions at times, such cases can affect the efficient running of the enterprise. In some organizations, there exist clear conflicts between line and staff. Minimized co-ordination among the two authorities hampers competitiveness of the organization. Maintaining high remuneration of support cadres is costly, especially for organizations with limited finance. Moreover, the satisfaction of both line and staff officials is very important for effective results. 


\subsection{Distribution of Skill Levels among Employees as a Yard Stick for Competitiveness}

In this study, the FSL employees were categorized into core function (laboratory employees) and support staff. Within, the laboratory employees category, different categorization has been used based on levels of skills, that is, professionals (principal level), skilled (senior employees), semi-skilled (below senior level) and non-skilled employees (laboratory attendants), as shown in Figure 5. The distribution of professional and skilled employees observed has been changing from the year 2000 to 2015 , due to a competitive organizational culture built on the following key features: employee ownership, employee attitude and job satisfaction, team versus individual learning, continuous learning, strategic planning, leadership, etc. Based on the growth of skills and employment laws, the employees are always migrating from semi-skilled to skilled and finally to professional levels due to continuous measures of performance and promotions. From 2004/5, the number of semi-skilled employees has been on a rise due to continued employment (initially at a slow rate).

Based on the number of professionals, which increased from about $10 \%$ in (the yean $2000 / 2001$ ) to $30 \%$ in $2006 / 2007$, it is evident that a large pool of employees ready for promotion existed. Considering the number of laboratory professionals who exited the employment cycle due to transfer, retirement, death, etc., the fact that the fraction of professionals remained high between 2003/4 and 2011/12 (above $20 \%)$ is an indication of a strong retention, succession and training program in the FSL. The fraction of professionals dropped from 24\% to $15 \%$ between $2011 / 12$ and 2014/15 due to an increase in skilled employees (caused by promotions) and also due to entry of new employees in semi-skilled level. The fact that the percent

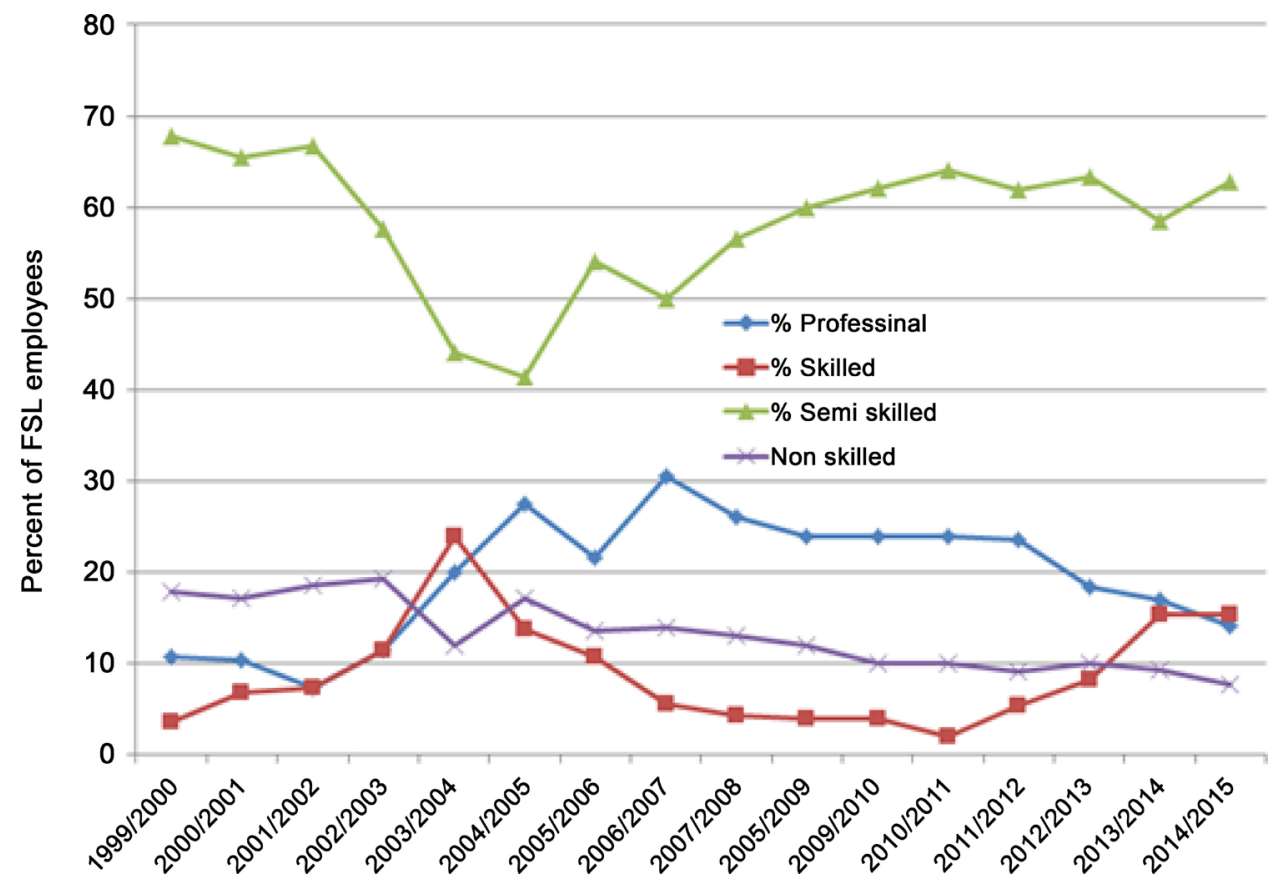

Figure 5. Variation percentage of the FSL skill levels with time. 
of non-skilled employees was decreasing from $20 \%$ in $2003 / 04$ to $8 \%$ in the year 2015 shows that the laboratory was creating more of the semi-skilled to professional to skilled and professional employees by employing more graduates, which puts the FSL at a competitive advantage. Whether the professional and skilled employees are performing their leadership functions and succession obligations according to required standards, remains a question to be answered by the FSL management team.

Figure 6 shows a snapshot of the distribution of the skill levels in the FSL for the period from 1999 to 2015 . The radar chart with markers shows the percentage of the skill levels starting with the all-time highest component of the FSL employees, that is, semi-skilled, followed by professional level which started at a very low level and which has been, however, decreasing recently. To lower extent, the skilled and non-skilled levels are shown at the center of the radar. The four pie charts surrounding the radar gives the snapshots of the composition of skill levels for the specified financial years: 1999/2000, 2004/05, 2009/10 and 2014/15. Taking the professional level, for example, it started at $10.7 \%$ in $1999 / 2000$, increased to $27.6 \%$ dropped slightly to $24 \%$ and then went down to $14.1 \%$ at the end of 2014/15 fiscal year. None of the skill levels were on continuous rise, stable or decrease. The fractions have been changing from time to time indicating that the distributions have been arising by chance, without planning. This calls for proper human resource planning, which is always a challenge in developing countries and also due to lack of mandate to effect employment by the FSL according to its plans.

\subsection{Promotion Timelines and Its Role on Professional Development in the FSL}

Figure 7 shows the history or timeline for the total number of promotions achieved

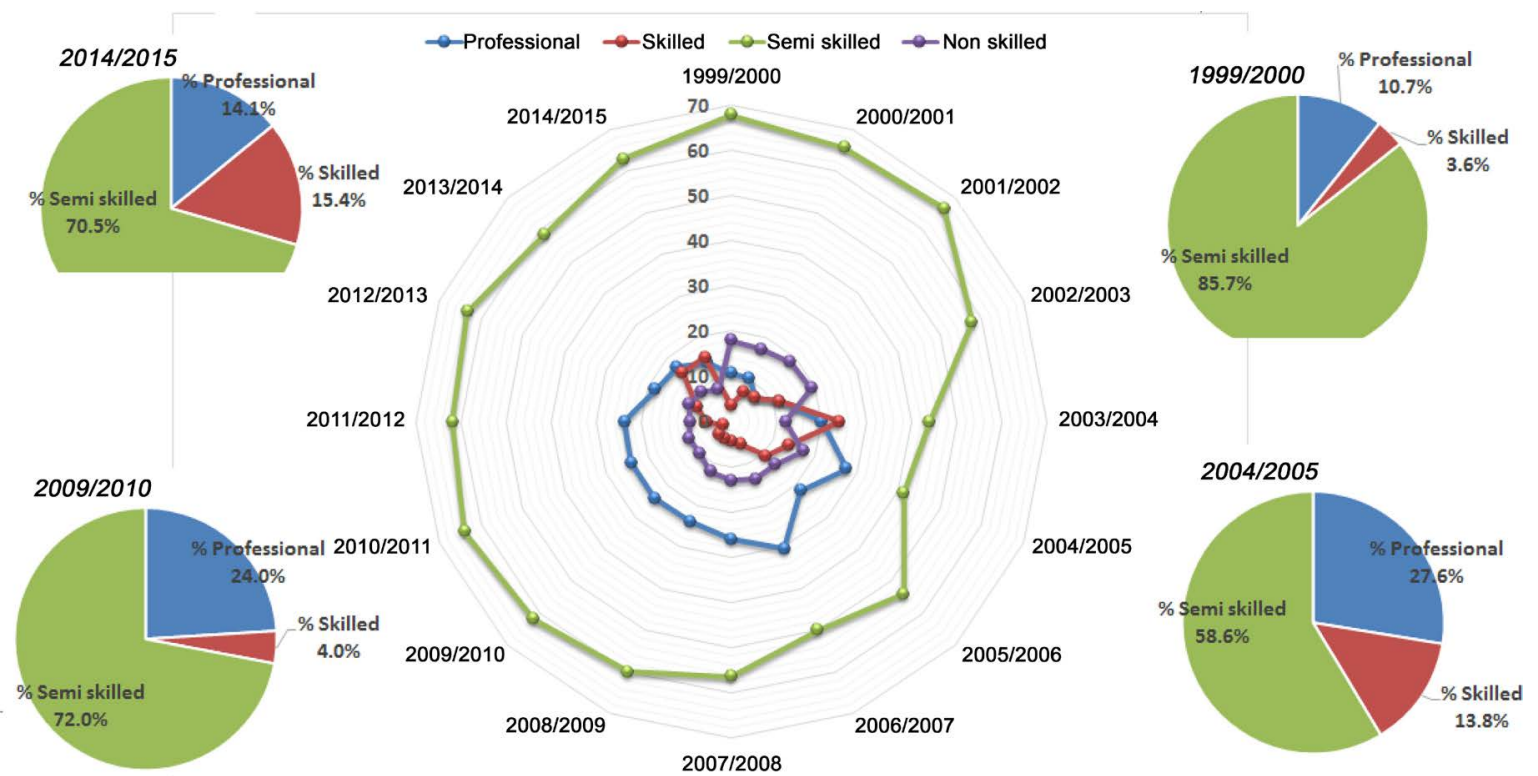

Figure 6. Distribution of the skill levels during different FSL eras. 


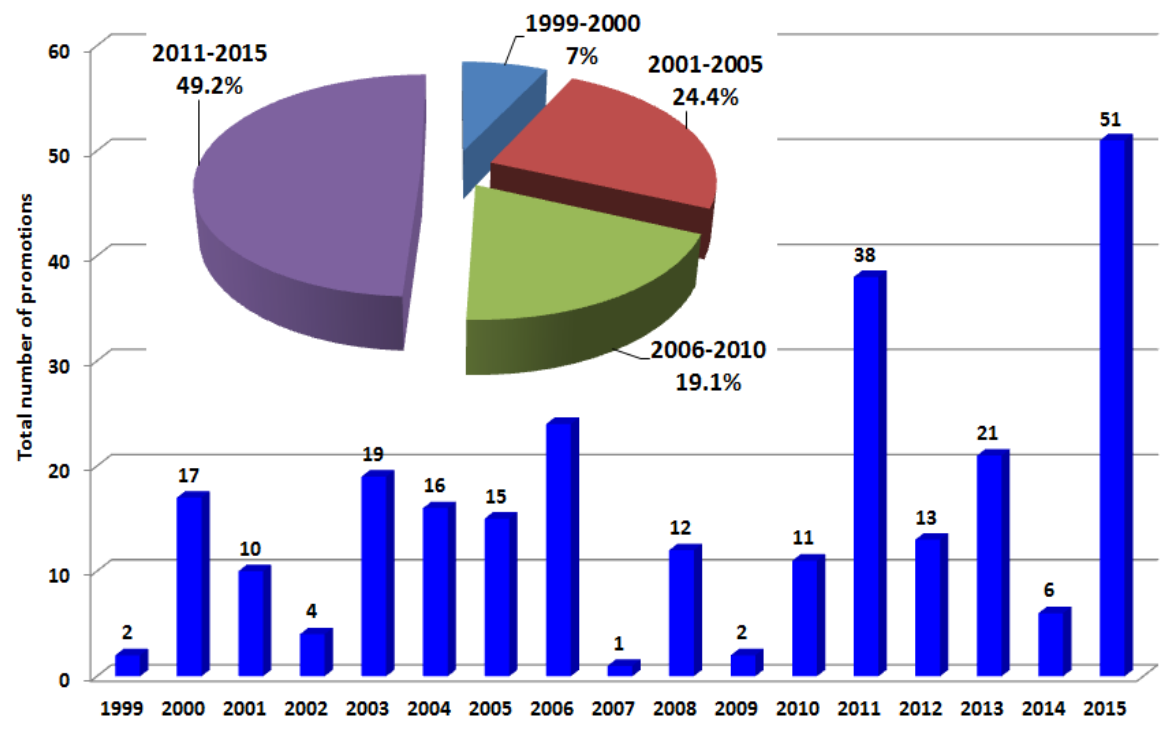

Figure 7. Promotions timelines during different eras of the FSL.

by GCLA employees from the year 2000 to 2015. Promotions are regulated or provided by a clear budget approved and released by the President Office's Public Service Management, and is not under direct control of the FSL. There are requirements that must be satisfied by GCLA employee, which together with budget allocation, guarantee promotions. From Figure 7, it is evident that promotions have been always granted to average of 10 per year, with highest number of promotions reaching 51 in 2015 and 38 in 2011. The rest of the years, it was observed that the number of promotions was not satisfactory compared to the total number of employees. A proper indicator is to determine the percent of employees promoted against total number of employees in that year. By grouping the data in 5 years interval, it is clear that most of the promotions took place between 2011 and 2015 (that is $49.2 \%$ of the promotions), as shown in the inserted pie chart.

\subsection{Analysis of Employee Stagnation Time}

\subsubsection{Comparison of the Maximum Stagnation between Different Professions}

Figure 8 shows the stagnation time in years for the three professions studied (chemists, technologists and accountants). The chemist profession shows the highest stagnation amongst the mentioned professions. This is due to the fact that chemists have to undergo long studies before they are promoted. However, this is also an indication of how experienced they have to be before they are promoted, although of three years is required.

The rank with the highest stagnation time is $\mathrm{E}$ which reveals how long all employees in this specific rank have served the organization for this specific period studied. Employees in the principal level form the backbone of the FSL. Stagnation times at the bottom of the professional development ladder (level A) is supposed to be long enough as it includes a young workforce ready for training as a 


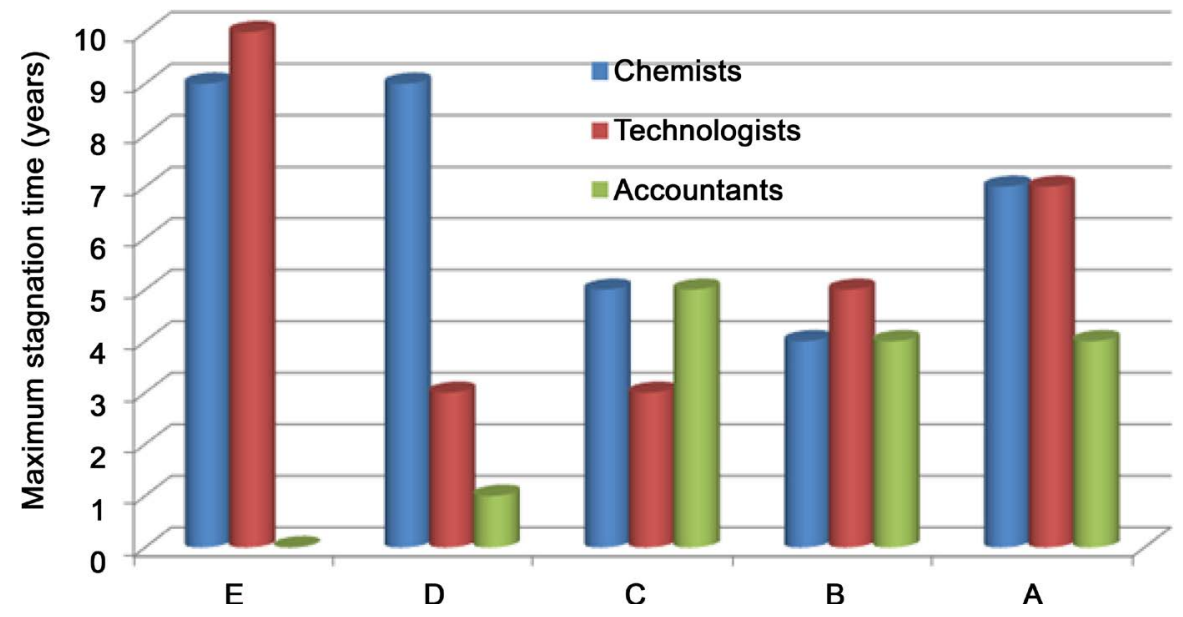

Figure 8. Maximum observed stagnation times for different ranks within professions.

part of the succession plan. This includes the chemist and technologist level II which are actually the work force of the FSL. Among the chemist, the shortest stagnation periods were observed for employees from senior to principal chemist's levels. Longest stagnation in the chemist II level followed by chemist I coincides with a requirement for FSL in order to create professionalism and proper understanding of the processes and gain enough hands on experience. Compared to technologist longer stagnation were observed for principal levels followed by promotion from technologist II to I. Finally, the accountants show shortest stagnation periods for all cadres where data was an available.

The maximum stagnation for ranks $\mathrm{E}$ and $\mathrm{D}$ signifies the length of time that FSL employees serve in the roles of leadership. Maximum observable stagnation times for different ranks within professions are shown in Figure 8. Longest times were observed in the professional or principal level which is an indication of times from last promotion to principal level to date for which there is no further promotion. Based on the analysis of the observed maximum stagnation times, the data presented in Figure 8 shows that there are principal chemists and technologists who have served at that level for 9 and 10 years, respectively. This is an added advantage for competitiveness of the FSL. For the chemist profession, another longer stagnation was observed for rank D, for up to 9 years, which comprised 3 employees waiting for promotion from senior to principal level. Because this is a level or rank still in professional development, such employees may show signs of dissatisfaction and complaints. Reasons for extended stagnation time include lack of budget and noncompliance to conditions for promotion other than time (performance, continuity at the current post, proper record keeping, etc.). Such cases need to be smoothened out in order to increase morale and productivity. With such extended stagnation time, some of the senior employees are experienced enough to deserve appointment to higher administrative posts.

The maximum stagnation times for ranks C, B, A, is justifiable for all professions. Moreover, it is still worth mentioning that the shortest maximum stagnation times were generally shown for accountants than for chemists and technol- 
ogists. This is because of availability of professional courses for support cadres in the country, allowing accountants to pursue training and earn certification faster, while professional courses are not available for chemists and technologists. Moreover, training for most of the support cadre, like accountants, do not require laboratory work different from chemists and technologists.

\subsubsection{Minimum Stagnation for Different Cadres and Ranks}

Minimum stagnation time indicates how faster employees were promoted compared to the three years stated by the public service regulations. The minimum stagnation time observed ranged from 1 to 3 years for all professions. Since the Government regulations stipulates 3 years minimum, then serving a position for only 1 year before promotion is an indication of poor compliance to regulations. The data presented in Figure 5 and Figure 6 spans a period from the year 2000 to 2015 , indicating that noncompliance to regulations is a problem facing the public employees for a long time that need attention of the FSL management all the time. Promotion to higher ranks before 3 years leads to FSL with who are not competent enough to serve the next level or rank. Reasons for such discrepancy include poor record keeping, lack of communication between FSL and POPSM, etc. Figure 9 compares the minimum stagnation time observed for different professions at the five levels of professional development.

The lowest minimum stagnation of 1 year to move from one rank to another was observed for all professions (chemists, technologists and accountants), being a critical problem for chemists and technologists which need to demonstrate strong competence in all stages $\mathrm{A}$ to $\mathrm{E}$. Levels $\mathrm{C}$ and $\mathrm{B}$ shows a required minimum stagnation of 3 years for accountants and technologists only. Comparison between Figure 8 and Figure 9 shows that there are cases where maximum and minimum stagnation times are equal. This is a case of accountants at level D where the stagnation time was only one year, being a violation of regulations in both cases.

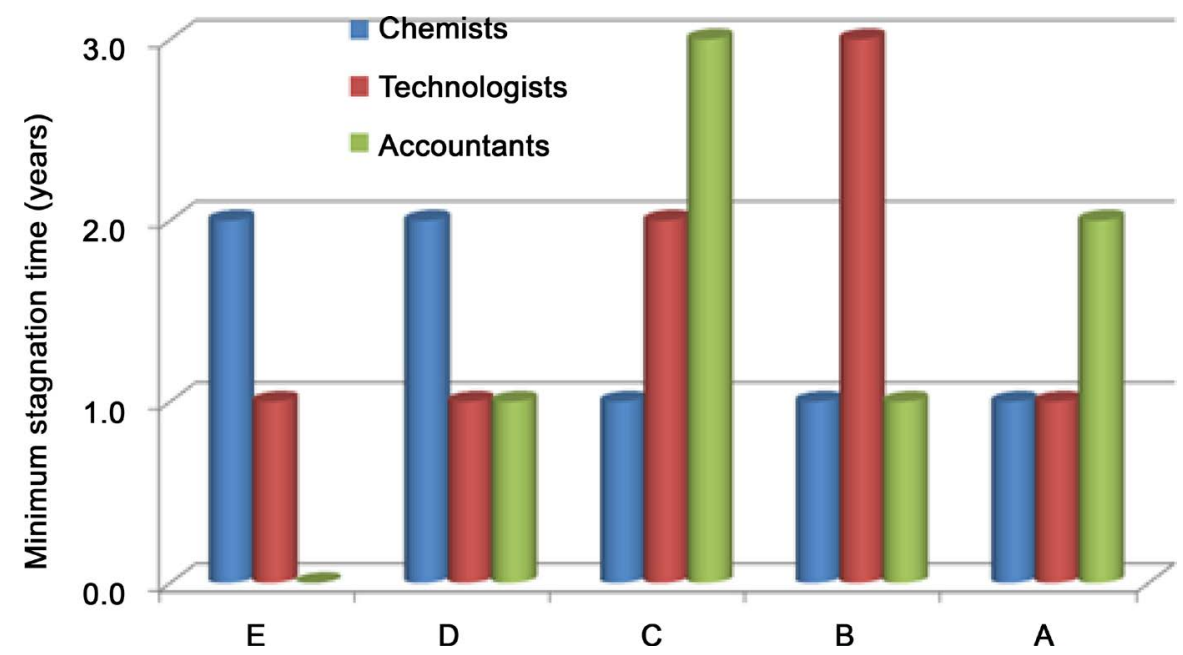

Figure 9. Minimum stagnation time observed among FSL employees for different professions. 


\subsection{Quantification and Analysis of Total Service Time at Different Professional Ranks}

\subsubsection{Total Service Years at Different Professional Ranks}

In this study, lack of promotion from one professional level to another (or stagnation) was also given a positive consideration that employees get enough time (in years) to serve the organization at that professional level (expressed as service years). The total number of years served by all employees in that particular level will also indicate which profession served more years (which depends also on the number of employees). Figure 10 shows the total service years' data specifically for chemists, technologists and accountants. For chemists, most of the time was served in level A (180 service years) followed by level B, which shows 100 service years. The number of service years for chemists are lower for levels $\mathrm{C}$ to $\mathrm{E}$ although a slight linear increase is indicated. As more and more chemists and technologists are promoted to higher levels with time, levels $\mathrm{D}$ and $\mathrm{E}$ will continue to rise as well (assuming lower turnover rate), ultimately, leading to more service years at level E, where there is no further promotion. Current levels of service years for professional chemists (principal level) is 60 service years, which is not enough for satisfactory leadership competence development and succession plan implementation required to boost the competitiveness of the FSL.

\subsubsection{Total Employees Service Years at Different Professional Ranks}

Figure 11 shows the overall total service years (for all professions combined, in that specific ranks or levels). It was still observed that in levels A and B employees served for many years (248 and 131 service years, respectively) which were served by lower cadres which normally comprise of large numbers of employees. It is interesting to note that level $\mathrm{E}$ (principal level) shows larger number of service years, at 94 service years compared to levels $C$ and $D$ which shows minimum number of years for the FSL. Levels $\mathrm{C}$ and D are also known as regarded as transition levels. Moreover, level D contributes strongly to the leadership capability, since managers for laboratories are normally senior chemists (in level D).

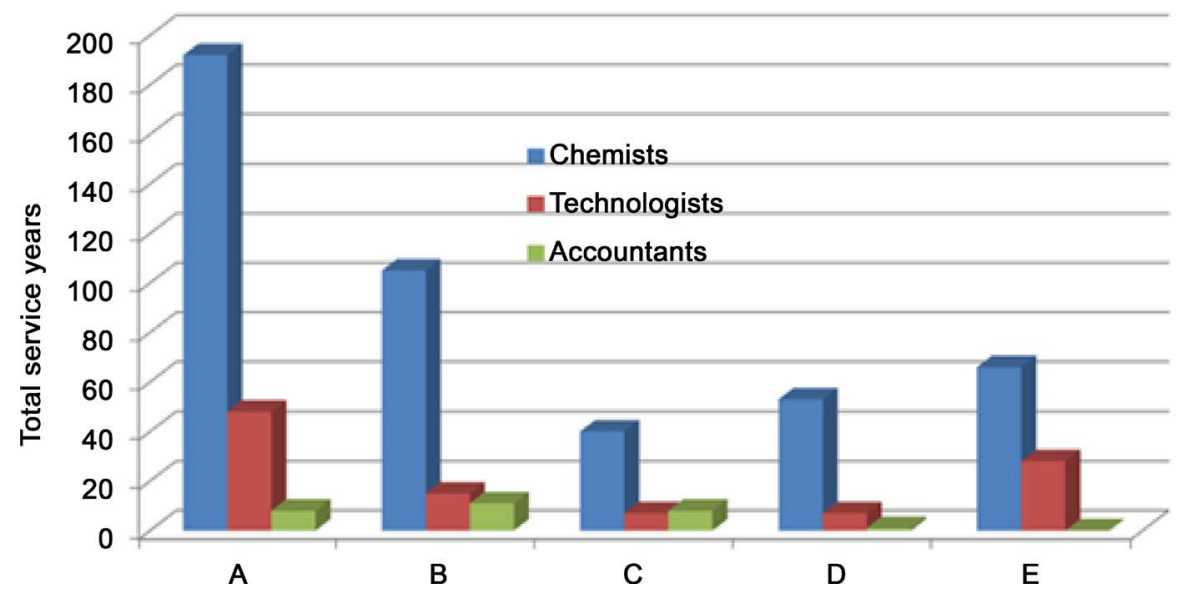

Figure 10. Total number of employees' service years at different professional ranks. 
The data presented in Figure 10 and Figure 11 was then used to determine different indices developed in this study using Equations (1) to (6), as shown in the Table 4. While Figure 11 excludes the 17 years served by the assistant accountants, Table 4 includes this time into rank A. Based on Figure 11, the competence capability, $\Omega_{E}=94$ years, the leadership capability, $\Omega_{E D C}=210$ years while professional development time for lower cadres, $\Omega_{A B}=379$ years.

A value of $P D I=0.65$ implies that $65 \%$ of the years served by the FSL employees are served by the lower ranks $\mathrm{A}$ and $\mathrm{B}$ which are still developing professionally, and still depending on the training and couching from the employees in the levels from senior to principal level I. On the other hand, a specific competence index, $L C I_{s}=0.157$ implies that there is $15.5 \%$ of the service years served by the FSL employees in the principal I level during which the latter are supposed

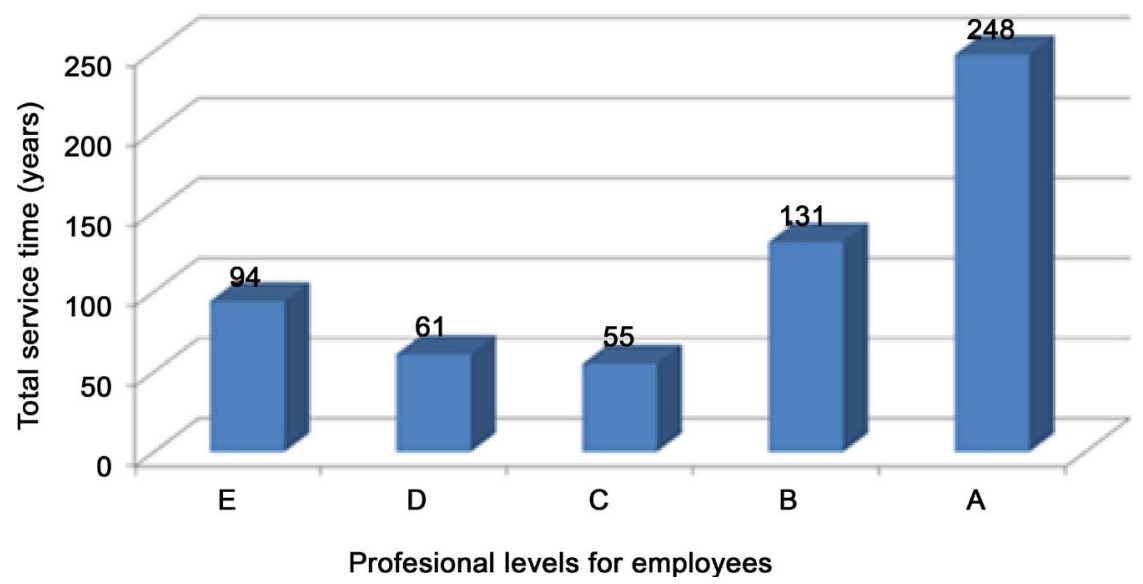

Figure 11. Distribution of total service years according to ranks in the FSL.

Table 4. Determination of different indices for professional development of FSL employees using overall service years' data.

\begin{tabular}{cccccc}
\hline Rank & E & D & C & B & A \\
\hline Chemists & 66 & 53 & 40 & 105 & 192 \\
Technologists & 28 & 7 & 7 & 15 & 48 \\
Accountants & 0 & 1 & 8 & 11 & 16 \\
Overall total stagnation time (years) & 94 & 61 & 55 & 131 & 256 \\
Grand total longevity/stagnation (years), $\Omega_{\text {tot }}$ & & & & & 597 \\
Competency capability (years), $\Omega_{E}$ (years) & & & & & 94 \\
Leadership capability in years, $\Omega_{E D C}$ (years) & & & & & 210 \\
Professional development time for lower cadres, $\Omega_{A B}$ (years) & & & & & 387 \\
Professional development index, $P D I$ & & & & & 0.650 \\
General leadership competency index, $L C I$ & & & & & 0.352 \\
Specific leadership competence index, $L C I_{s}$ & & & & & 0.157 \\
General succession index for FSL, $S I_{g}$ & & & & & \\
Specific succession index for FSL, $S I_{s}$ & & & & & \\
\hline
\end{tabular}


to be transferring skills to the rest of the FSL employees. However, this depends on their willingness to transfer skills and knowledge sharing with other employees. A specific succession index, $S I_{s}=0.242$, based on Equation (6), indicates that the years served by employees in the FSL at principle level $\mathrm{E}$ while transferring knowledge and skills to the lower ranks $\mathrm{A}$ and $\mathrm{B}$, to prepare then take over their positions as successors is about only a quarter of the total time served by the latter group. Thus, the principle level $\mathrm{E}$ employees are supposed to be enabled to make sure they actually prepare the employees in the lower ranks by implementing a well-designed succession plan.

Based on Table 4, the overall values of professional development index (PDI), leadership competency index $(L C I)$ and succession index $(S I)$ were determined for the first time in this study. Currently, the indices could not be compared, but the results sets a baseline for the organization to continue tracking such indices as good indicators of a strategic plan implementation.

\subsection{Analysis of Indices Based on Employees' Service Years}

\subsubsection{Values of Professional Development Index for Different Professions}

Professional development index, PDI, on the other hand, is a measure of the demand posed by the lower ranks as they serve within the FSL. The index signifies the ratio of the total service years for employees requiring professional development (levels $\mathrm{A}$ and $\mathrm{B}$ ) to the overall total service years. Being a bottom-top demand, the $P D I$ is different from the $L C I$ and SI which look at the delivery of skills from higher cadres to the lower cadres, that is, top-bottom view. Figure 12 shows a comparison of the values of the $P D I$ for chemists, technologists and accountants. The $P D I$ was observed to be highest for chemists, indicating that the lower cadre chemists, served the FSL for many years, while struggling for development offered through on job training (OJT), hands on training, supportive supervision and instructions from their predecessors serving the FSL in the higher

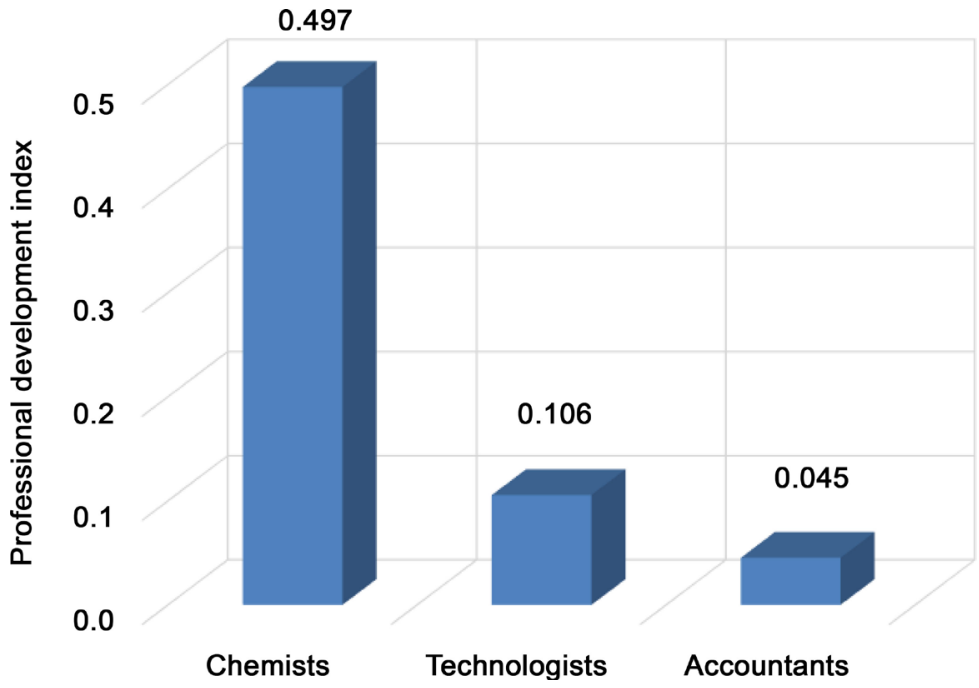

Figure 12. Values of professional development index (PDI) for different professions in the FSL. 
levels or ranks in the professional development ladder. A professional development index, $P D I=0.497$ implies that $49.7 \%$ of the total service years by chemists were served in the lower ranks A and B (chemist I and II), while relying on their predecessors for professional development. Other means of professional development can include self-initiatives and readiness to learn, further training in higher learning institutions, joining professional bodies, etc.

\subsubsection{Comparison of Leadership Competency Indices between Different Professions}

As stated above, the leadership competence for the FSL depends on the number of employees and how much time they have served in the ranks starting from senior to principal level I (that is, levels C, D and E). Assuming that the employees in these levels are delivering leadership functions correctly, it is expected that the lower cadres in levels A and B will be able to gain leadership skills accordingly as they develop professionally ready for promotion into higher ranks. Figure $13 \mathrm{com}$ pares the values of leadership competency index (both general and specific) between different professions (chemists, technologists and accountants). The specific leadership competency index $L C I$ was observed to be highest for chemists followed by technologists, while the index was zero for accountants for which none of the employees were in principal level E. The general leadership competency index followed the similar trend for the three professions, being higher than the specific values. Thus, chemists are supposed to have played a bigger role in leadership for the whole FSL compared to other professions. The management is thus supposed to provide leadership training for chemists to make a positive use of their service years and hence build FSL competitive edge.

\subsubsection{Analysis of Specific and General Succession Indices}

From the year 2000 to date, the FSL has not established and implemented a concrete succession plan and hiring was only ad-hoc depending on government openings. Through succession planning, future leaders are prepared to step into the shoes of the current leaders a process which is important for a government laboratory. Succession planning is an important aspect of FSL's human resources as it allows

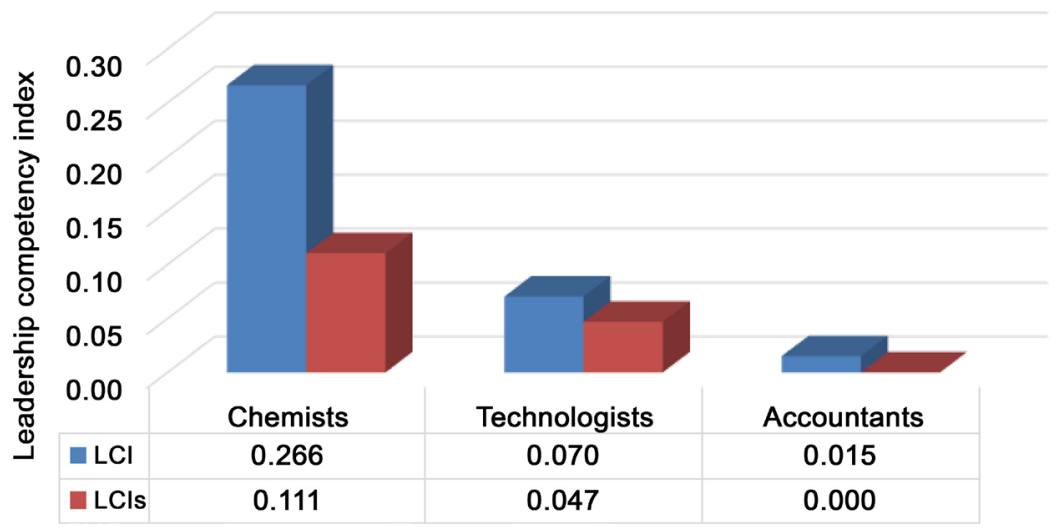

Figure 13. Values of leadership competency index (LCI) for different professions in the FSL. 
laboratory activities to continue smoothly forward during inevitable leadership changes. Succession in FSL is needed and is done in the form of training in basic supervisory and interpersonal skills for managers to avoid a ripple effect throughout the organization causing lower motivation and the loss of good employees. In addition, the lower-cadre employees should have the opportunity to work in conjunction with the manager they will be replacing in near future and thus learn the specifics of their new job or positions.

Succession analysis is about assessing if employees are developed to take bigger roles. In this study, the total number of service years for all professions was used to measure succession index. The ratio between the total service years served by the principal employees in level $\mathrm{E}$ to the total service years served by the ranks $A$ and B was used to measure succession as per Equation (6). Under normal circumstances, the number of principal employees is smaller than those in lower ranks. However, this study considered not only the numbers but also the total service time by employees in the respective levels. The study assumes that there was high tendency of the smaller group of professionals to transfer skills and knowledge to the large group, from which a good number of professionally growing employees can be realized to take over the bigger roles. The common quantitative measure of succession is the number of leadership vacancies filled by internal candidates based on their readiness, compared with the number of posts that had to be filled through external hires. For the period under study, almost all the leadership vacancies were filled by internal candidates with principal (directors) and senior (mangers) ranks, most of which were new posts due to newly proposed organization structure.

To assess the strength of succession for different professions within the FSL, succession indices were determined for chemists, technologists and accountants, as presented in Figure 14. Specific succession index was used to represent the ration of professionals (principal employees only) to other employees for each

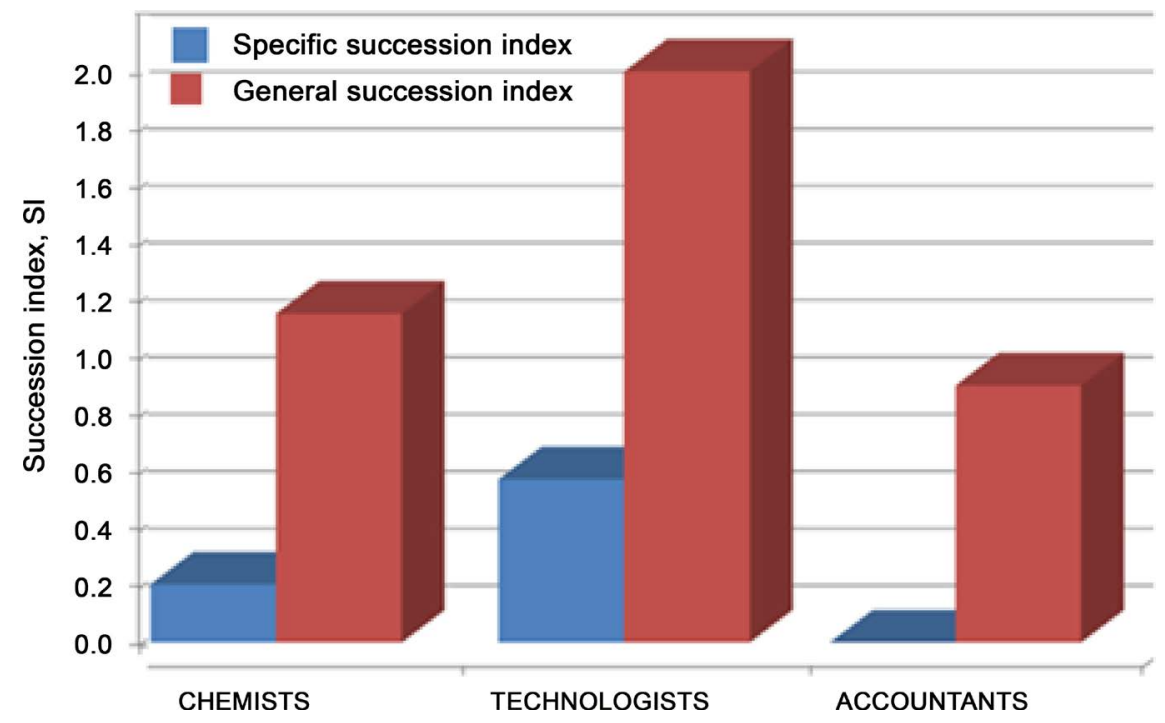

Figure 14. Values of succession indices for the three professions within FSL. 
profession, while the general succession index was used to represent the ratio of senior and principal employees combined to other employees. Specific succession index was observed to be higher for technologists than chemists. Having no principal accountants in the study period, led to zero value of $\mathrm{SI}_{\mathrm{s}}$ for accountants (as shown in Figure 14). Similarly, the general succession index was highest for technologists followed by chemists and lastly accountants. Results show that the FSL has most technologists serving in the principal level (highest specific succession index) while the highest general SI value indicates that there is twice the number of years served by technologists in the principal level I and II and senior level than in the lower levels. This means, the value of $\Omega_{E D C}$ is twice as higher as the $\Omega_{A B}$. Also, the results indicate that there was a small number of years served by technologists in the lower ranks compared to chemists. Very high general succession index for technologists can also indicate that they stagnate more and serve many years in the E, D and C ranks than for chemists and accountants. The observation that general succession index is above 1.0 implies that there has been a dry spell in the public employment system, such that few employees were employed while the former employees have moved to principal and senior levels especially technologists, while the lower cadres are fewer in number or were recently employed. Moreover, high specific succession index for technologists than chemists can also be attributed to large number of technologists in rank or level E, few technologists in ranks $\mathrm{A}$ and $\mathrm{B}$, or many years served in rank $\mathrm{E}$ for technologists than chemists.

Both specific and general succession indices are ratios of years served by employees in the FSL which are ready to transfer skills and experience to the junior cadres, compared to those who still need additional years of training. The specific and general succession indices are also metrics of laboratory bench strength for the FSL.

\subsection{Analysis of Employee Diversification within FSL}

The diversification of the employment categories utilized in the FSL requires human resource management to deal with new problems [8]. The first is how to combine personnel management policies, the nature of the duties assigned, wage and other remuneration systems in each employment category, that is, sensible formulation of employment categories (not practiced in public sector in Tanzania). A relatively unexplored alternative is the possibility that diversification creates richer and more active internal labor markets, leading to improved labor efficiency relative to focused firms.

Figure 15 shows the variation of diversification index against laboratory employees with time from 1999/2000 to 2014/2015. Given the advantages of diversification, it is evident that the observed increase in diversification from 2002/03 means the FSL was increasingly becoming more competitive. The observed growth in terms of diversified employment was highest in 2002/2003 due to addition of new roles, that is, implementation of the Industrial and Consumer Chemicals 


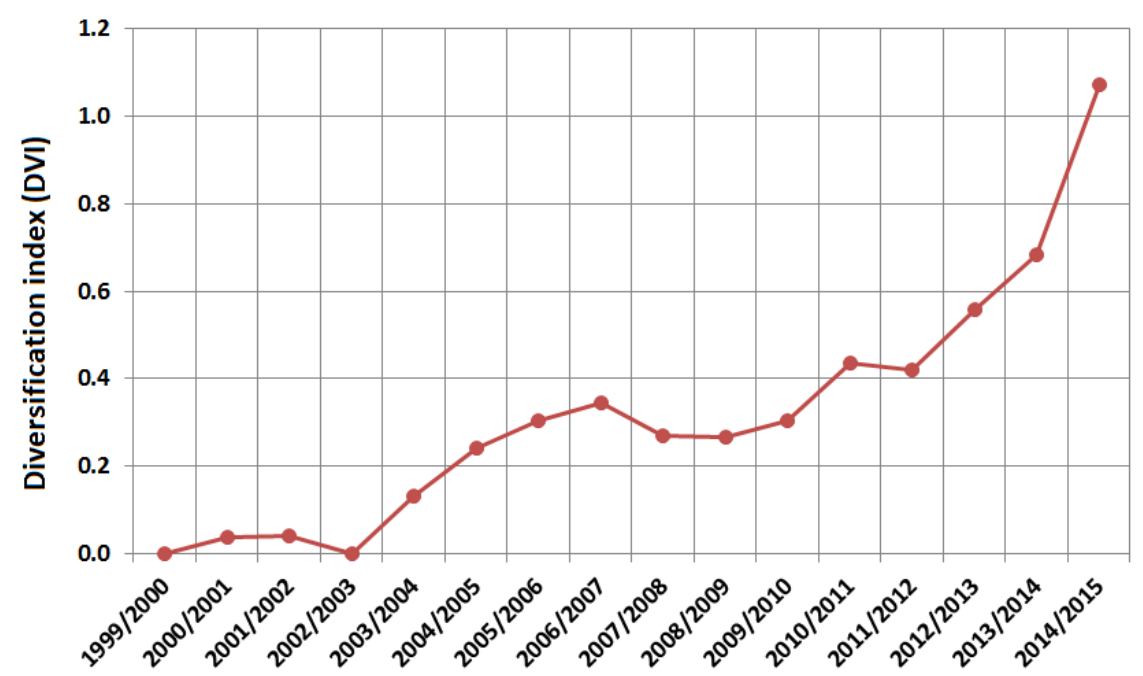

Figure 15. The variation of diversification index against laboratory employees from $1999 / 2000$ to $2014 / 2015$.

(Control and Management) Act (ICCA), enacted in 2003. This led to increase in diversification compared to the previous four financial years. With enactment of ICCA, the scope of activities increased, a new and clear market segment for FSL was established (based on new pool of stakeholders or clients dealing with chemicals importation, export, manufacture, use and distribution in Tanzania). This expanded not only the laboratory work but also the need for non-laboratory cadres increased, being an added advantage to the laboratory work in terms of finance and specialization. From 2005 to 2012, there was a clear continuous increase in DVI, until when new areas of ICCA implementation were invented, necessitating a need for new employees of diversified categories. This led to a faster increase in diversification index with reference to laboratory cadres. The rise in diversification in 2003/4 was also led by the need for FSL to expand geographically, from being concentrated in Dar es Salaam to opening of zonal office in Mwanza in 2004 and later in Arusha in 2007/8 during which diversification index was observed to increase due to a demand for support staff to assist in running and maintaining the new zonal offices.

The increase in diversification to about unity implies that the number of new support staff has tremendously increased becoming equal to the number of laboratory cadre especially from 2012 to 2015 . The first question is how to integrate different personnel management measures and the nature of duties assigned to individual employment categories within general personnel management policy. The second is how to maintain a balance of wages and other rewards among different employment categories. A number of employment sub-categories, where different employment conditions and wages and other types of remuneration are used for workers with different careers, are also implemented for these two main types but not practiced in public organizations like the FSL. It can thus be another important task to balance rewards among workers in various employment categories. 


\section{Conclusions}

The competitiveness of a Forensic Science Laboratory (FSL) based on employees' professional development and diversification into different professionals has been analyzed. The newly developed indices have been successfully used to assess the competitiveness based on employees' total service time in years at different ranks. The number of employees for support cadres increased faster in the last 5 years from $34.3 \%$ in $2009 / 2010$ to $57.1 \%$ in $2014 / 2015$ compared to chemists and technologists which form the core laboratory cadre. The increasing tendency of the staff-to-line ratio (SLR) from the year 2000 to 2015 and reaching above 0.8 from 2013 to 2015 is an indication that the FSL has been undergoing diversification and division of labor. The FSL workforce comprises of mainly semi-skilled employees necessitating professionals to effectively exercise leadership roles.

Promotions for FSL employees play a key role in their professional development, based on which, the time series of number of promotions is encouraging. High stagnation of employees at specific ranks up to $9-10$ years has been observed in some cases but some employees were promoted to higher level before the period of 3 years stipulated by public service regulations, indicating poor compliance to regulations. The maximum stagnation times of $9-10$ years observed for rank $\mathrm{E}$ and D could lead to employee frustrations, lower morale and engagement. The total service times of employees in the FSL were observed to be higher in ranks A and $\mathrm{B}$ for chemists compared to other ranks.

Indices developed in this study ( $L C I, P D I, S I)$ form a baseline data for strategic analysis of FSL competitiveness in the future and allow for proper human resource planning and monitoring. Chemists show highest demand for professional development and leadership competence indices based on the service years compared to technologists and accountants. In the FSL shows a higher succession index was observed for technologists compared to chemists and accountants. Employee diversification in the FSL has been increasing from 2003 to date attributable to the enactment of ICCA in 2003 and HDNA Act in 2009.

It was further concluded that the FSL competitive advantage is improving, which requires attention of the management team in order to maintain this level.

\section{Acknowledgements}

The authors are grateful to the GCLA management for support during the course of this study. Special thanks to the Human Resource Management Office (B. Lankii, G. Kasembe and A. Mapunda) for their assistance during employees' data collection and organization of the database.

\section{References}

[1] Desimone, L.A. (2011) A Primer on Effective Professional Development. Phi Delta Kappan, 92, 68-71. https://doi.org/10.1177/003172171109200616

[2] Akhigbe, O.J. (2013) Human Resource Planning: A Key Factor in Ensuring the Effectiveness and Efficiency of Organization. Journal of Emerging Trends in Eco- 
nomics and Management Sciences, 4, 388-396.

[3] Yalabik, Z.Y., Swart, J. Kinnie N. and van Rossenberg, Y. (2016) Multiple Foci of Commitment and Intention to Quit in Knowledge-Intensive Organizations (KIOs): What Makes Professionals Leave? The International Journal of Human Resource Management, 28, 1-31.

[4] Yalabik, Z.Y., Rossenberg, Y.V. Kinnie, N. and Swart, J. (2014) Engaged and Committed? The Relationship between Work Engagement and Commitment in Professional Service Firms. The International Journal of Human Resource Management, 26, 1602-1621. https://doi.org/10.1080/09585192.2014.953972

[5] Devi, S. and Basariya, R. (2017) Career Plateau of Employees and Its Causes. International Journal of Advanced Research in Science, Engineering and Technology, 4, 3589-3592.

[6] Gittell, J.H. (2002) Relationships between Service Providers and Their Impact on Customers. Journal of Service Research, 4, 299-311. https://doi.org/10.1177/1094670502004004007

[7] Gittell, J.H., Seidner, R. and Wimbush, J. (2010) A Relational Model of How High-Performance Work Systems Work. Organization Science, 21, 490-506. https://doi.org/10.1287/orsc.1090.0446

[8] Geare, A., Edgar, F. McAndrew, I. Harney, B. Cafferkey, K. and Dundon, T. (2014) Exploring the Ideological Undercurrents of HRM: Workplace Values and Beliefs in Ireland and New Zealand. The International Journal of Human Resource Management, 25, 2275-2294. https://doi.org/10.1080/09585192.2013.876441

[9] Iveta, G. (2012) HR-Planning and Mutual Connection with the Perspective Strategic Goals. Journal of Competitiveness, 4, 117-128.

[10] Jackson, S. and Schuler, R. (1990) Human Resource Planning: Challenges for Industrial/Organizational Psychologists. American Psychologists, 45, 223-239.

https://doi.org/10.1037/0003-066X.45.2.223

[11] Feldman, D.C. and Weitz, B.A. (1988) Career Plateaus Reconsidered. Journal of Management, 14, 69-80. https://doi.org/10.1177/014920638801400107

[12] Wang, S-L. and Wu, P.-Y. (2008) The Role of Feedback and Self Efficacy on Web-Based Lerning: The Social Cognitive Perspective. Computers and Education, 51, 1589-1598. https://doi.org/10.1016/j.compedu.2008.03.004

[13] Drucker, P.F. (1999) Knowledge-Worker Productivity: The Biggest Challenge. California Management Review, 41, 79-94

[14] Swart, J., Kinnie, N., van Rossenberg, Y. and Yalabik, Z.Y. (2014) Why Should I Share My Knowledge? A Multiple Foci of Commitment Perspective. Human Resource Management Journal, 24, 269-289. https://doi.org/10.1111/1748-8583.12037

[15] Chan Kim, W. and Mauborgne, R.E. (1998) Procedural Justice, Strategic Decision Making, and the Knowledge Economy, Strategic Management Journal, 19, 323-338. https://doi.org/10.1002/(SICI)1097-0266(199804)19:4<323::AID-SMJ976>3.0.CO;2$\underline{\mathrm{F}}$

[16] Hislop, D. (2003) Linking Human Resource Management and Knowledge Management via Commitment: A REVIEW and Research Agenda. Employee Relations, 2, 182-202. https://doi.org/10.1108/01425450310456479

[17] Lin, H.F. (2007) Knowledge Sharing and Firm Innovation Capability: An Empirical Study. International Journal of Manpower, 28, 315-332. https://doi.org/10.1108/01437720710755272

[18] Ravishankar, M.N. and Pan, S.L. (2008) The Influence of Organizational Identifica- 
tion on Organizational Knowledge Management (KM). The International Journal of Management Science, 36, 221-234.

[19] Becker, T.E. and Kernan, M.C. (2003) Matching Commitment to Supervisors and Organizations to In-Role and Extra-Role Performance. Human Performance, 16, 327-348. https://doi.org/10.1207/S15327043HUP1604_1

[20] Shaban, A. (2016) Managing and Leading a Diverse Workforce: One of the Main Challenges in Management. Procedia-Social and Behavioral Sciences, 230, 76-84. https://doi.org/10.1016/j.sbspro.2016.09.010

[21] Kinnie, N. and Swart, J. (2012) Committed to Whom? Professional Knowledge Worker Commitment in Cross-Boundary Organizations. Human Resource Management Journal, 22, 21-38. https://doi.org/10.1111/j.1748-8583.2011.00172.x

[22] Jørgensen, F. and Becker, K. (2015) Balancing Organizational and Professional Commitments in Professional Service Firms: The HR Practices that Matter. The In ternational Journal of Human Resource Management, 26, 23-41.

https://doi.org/10.1080/09585192.2014.925947 